\title{
Editorial
}

\section{¿Sociedad del conocimiento?}

Por los ocultos ojos del sueño descubro la lluvia persistiendo sobre el espejismo futuro, la niebla hacinada de sombras y el laberinto de lenguas indecibles, donde se confunde el entendimiento. Antonio Tello

Hoy en día es frecuente hablar sobre "la nueva era de la información" o la sociedad del conocimiento. Y si bien hay divergentes opiniones en torno a la expresión, opiniones influenciadas por ideologías, creencias y "visiones de mundo", por otro lado, nadie puede negar que algo nuevo está sucediendo y que gran parte de esa novedad la constituyen los cambios tecnológicos en los campos de la informática y las telecomunicaciones. Qué tanto el "artilugio" es verdaderamente la fuente de una nueva cultura, y en qué medida, es lo que está por verse. 
Lo típico de nuestra época no son los "nuevos" temores y esperanzas, sino la consciencia de que en el planeta entero compartimos unos temores y unas esperanzas. Habitamos en un mundo globalizado, no porque sea homogéneo, o porque se hayan realizado los sueños de unidad modernos, sino porque cada vez es más claro que afrontamos retos globales. Además, experimentamos vidas aceleradas. Nuestras formas de desempeño vital se han transformado según coordenadas temporales de rapidez, efectividad y simultaneidad que, aunque tienen su raíz en la racionalidad instrumental capitalista desde sus inicios, no podrían haberse desarrollado con suficiente eficacia sin las posibilidades que brindan las nuevas tecnologías de la información y la comunicación.

En la infosfera han muerto la distancia y el tiempo, y esto no en un mero sentido metafórico. Unas cuantas pulsaciones en un teléfono móvil nos mantienen conectados con cualquier parte desde cualquier otra. Durante la anterior campaña electoral, pudimos enterarnos de los resultados de la última encuesta - divulgada horas antes del propio día de las votaciones, lo cual está prohibido por el código electoral-, leyéndolos en Internet y pasando por encima de las leyes del país que prohibe su divulgación. ¿Recordamos las viejas nociones de frontera? Por otra parte, ¿puede significar algo el tiempo cuando la información digitalizada se desplaza de un lugar a otro en cuestión de segundos, convirtiendo los husos horarios y las nociones de "ayer" y "hoy" en algo irrelevante? Es frecuente escuchar que un determinado procedimiento, transacción u operación se realiza "desde cualquier lugar y en tiempo real", que viene a ser un mero eufemismo para señalar que se trata de una acción que no tiene nada que ver con nuestras decimonónicas concepciones del tiempo y el espacio.

Pero una sociedad no es sólo realidad, no es sólo lo que ya nos acontece, sino que "es" también aquello que queremos que sea: es también horizonte. No debemos olvidar que muchas de las entusiastas ovaciones que se dirigen a las nuevas tecnologías 
no nos deparan automáticamente todas las bondades de las que se enorgullecen sus promotores. Aún falta mucho por recorrer, no sólo en el nivel meramente técnico, sino también en los aspectos organizativos y burocráticos, las facilidades económicas, el ordenamiento jurídico y ético, la comprensión de las sensibilidades sociales y culturales... La vida en nuestra era implica un situs muy preciso: en lo espacial, globalidad; en lo temporal, simultaneidad (Manuel Castells) Y eso significa que hay que tomar decisiones y realizar tareas concretas. Las distancias se achican y el tiempo deja de ser relevante. Y, donde para muchos la consecuencia es obvia (¿qué nos detiene abora?), para otros existen fuertes dudas sobre si nuestros parámetros morales y reflexiones éticas avanzan al ritmo que lo hacen los cambios tecnológicos, sociales y culturales. O, quizás, lo que más nos inquieta es que se crea que la oleada de innovaciones no necesita ser cuestionada o sometida a más criterio que el suyo propio. Lo que sucede es que, en la actualidad, así como toda respuesta a las inquietudes humanas debe pasar necesariamente por la tecnología, todo proyecto "humano" debe recibir su aprobación. Esto nos deja cara a cara con quien dobla las campanas: la tecnología es, hoy por hoy, EL INTERLOCUTOR, el gran referente.

Una versión extrema del tecnocentrismo contemporáneo es cierta noción de progreso que está arraigando en científicos, burócratas y "tecnófilos": aquella en la cual el progreso tiene características de huida. Entre los que no ignoran que la tecnología puede ser también radicalmente desigual y cruel, se está suscitando un nuevo pathos, una nueva sensibilidad: el suspiro por la velocidad de escape, es decir, la tentación por la evasión definitiva de nuestras "vasijas de barro", gracias a los "propulsores tecnológicos”. Algunos utilizan la expresión “teología del asiento eyectable" (Mark Dery); otros, prefieren hablar de "medium televisivo" (P-Orridge). Ahora bien, unos y otros se refieren al fenómeno que se está convirtiendo en algo más que mera excentricidad: la nueva situación del hombre es la de alguien que pretende huir hacia adelante. El "progreso" no es más “de la huma- 
nidad", sino sólo de "algunos elegidos": aquellos que logren "conectarse" a la nueva vida, a la vez que "desenchufan" el cable que los ata a las miserias del cuerpo y de lo "orgánico". Liberación sí, pero no para todos, ya que la tecnología no da para tanto. La "gran desconexión" incluye dejar atrás al resto de "unidades orgánicas", empecinadas en vivir atadas a sus viejas formas de vida o, como algunos afirman con total cinismo, obligadas a quedarse en el "viejo mundo" porque llegaron tarde a la repartición de las capacidades y de la tecnología. Los que no están conectados (on-line) pertenecen a una nueva "clase" de desposeídos: son pobres informacionales.

Determinada crudamente por factores económicos, geopolíticos, militares, etc., la tecnología no será nunca el Dios paternal del Nuevo Testamento, ni el "terriblemente justo" del Antiguo, ni el transcendente fundamento del imperativo universalista kantiano: estamos ante un dios sin rostro humano, un "salvador" despreocupado de los individuos, un amasijo de cables y pernos. Nuestras posibilidades tecno-teológicas no nos dejan más opciones que la gélida María de Fritz Lang o el simpático asesino de Stanley Kubrick, HAL-9000. Entonces, no extraña que los viejos anhelos de tantas generaciones de humanos, como el de un "rapto hacia los cielos", sean identificados con el ciberespacio o la realidad virtual. Paradójicamente, donde algunos ven grandes posibilidades para el desarrollo de nuestra vida social, otros encuentran el "carro de fuego" que los evada del mundo de miserias... y de los miserables que se queden en él. Podemos hablar entonces de un posthumanismo tecnológico.

En la mayoría de discursos que pregonan a los cuatro vientos las bondades de la "nueva sociedad", llama la atención la identificación entre conocimiento e información, lo cual, si nos detenemos a pensar seriamente en ello, no es algo obvio. Está claro que conocer una cosa implica manejar datos sobre ella, pero no basta esto si no sabemos cómo ordenar, utilizar o interpretar esos datos. Y aunque no cabe duda de que esto es algo que está claro para un gran número de personas dedicadas a las ciencias 
de la información, no parece que sea así para los profetas informacionales. Es usual enfrentarse con la simple identificación entre el acervo de datos (información) y la capacidad para utilizarlos racionalmente (conocimiento). Las instituciones educativas, los organismos públicos y las empresas contemporáneas pueden fácilmente caer bajo el encanto de la promesa informacional, consistente en niños, burócratas y aspirantes a yuppies capaces de resolver cualquier problema, siempre y cuando respeten el principio de mantener, a toda costa, amigables relaciones con la interfaz del usuario. De esta fascinación por lo actual, lo cuantitativo y lo "digitalizable", a la eliminación de los programas de formación humanista y filosófica - con los conocidos argumentos de que tales "contenidos" son "inútiles", "poco prácticos" o, simplemente, "viejos"—no se necesita más que meros trámites burocráticos.

Es importante aclarar que no se trata de ignorar la importancia de las nuevas tecnologías o de lo cuantitativo. Tampoco es que la racionalidad instrumental, que subyace a los proyectos económicos o científicos, sea siempre el camino equivocado. Más bien, el peligro del reduccionismo tecnológico informacional consiste en la absolutización de un solo paradigma gnoseológico, que desprecia aquellas racionalidades que no se someten a la lógica de la explicación, a los modelos matemáticos o a los resultados concluyentes a partir de datos estadísticos. Lo que pueda aportar un modelo racional comprensivo, cualitativo, crítico y hermenéutico es visto como atavismo. ¿Interpretar? Para eso están los modelos matemáticos. ¿Crítica? No hace falta, isi los datos hablan por sí mismos! Puede que en el fondo se trate de una extrapolación interesada de lo que se conoce como redundancia. En palabras de Richard Dawkins:

Redundancia es un término de la jerga de la teoría de la información, que originalmente desarrollaron los ingenieros, preocupados por la economía de la capacidad de las líneas telefónicas. Información, en el sentido técnico, es el valor de la sorpresa, medida como el inverso de la probabilidad esperada. La redundancia es lo opuesto de la información, una medida de la falta de sor- 
presa, de lo anticuado. Los mensajes o partes de mensajes redundantes no son informativos, porque el receptor, en cierto sentido, ya sabe lo que está llegando (...) Gran parte del lenguaje hablado y escrito es redundante; por ello es posible el lenguaje condensado utilizado en el telégrafo: se pierde la redundancia, se conserva la información. (Los subrayados son nuestros).

Todos realizamos una cierta discriminación de los mensajes ante los que nos situamos día a día, por ejemplo, en función de su mayor o menor redundancia. Pero de esto no se sigue que debamos uniformizar nuestros criterios y habilidades para tal tarea de selección. Si no todo el correo electrónico que recibimos termina en la categoría "utilizable" —y "almacenable"-, no es porque nuestra selección siga un patrón uniforme, que debe su naturaleza únicamente a un determinado tipo de información, sino que hemos tenido que ejecutar un "comando" que es fundamentalmente un asunto de probabilidades, con las que debe contar nuestra libertad, a la vez que juega un papel esencial el contexto. En todo caso, los criterios que determinan nuestra selección son irreductibles a lo que "diga” este o aquel mensaje. Es más, podríamos aceptar que, en algunos casos, resulta relativamente sencillo "predecir" nuestros criterios de selección, pero debemos reconocer que no siempre terminará el mismo tipo de información en la papelera de reciclaje.

Los niños y jóvenes que son bombardeados con datos "útiles", ¿saben en qué medida, por qué y cuándo les son en verdad útiles? Si no poseen las capacidades para formular criterios coherentes, que les permitan discriminar eficientemente ante la avalancha de información, ¿sabrán utilizarla? Quizás no sea demasiado tarde para l $\neq$ lamar la atención sobre los abusos del informacionalismo y de su empeño por eliminar la "redundancia". Puede que todavía sea posible apostarle a una concepción del conocimiento abierta e integral, que reconozca el valor de la razón poética, humanista, así como del pensamiento histórico y crítico.

Es por lo anterior que, si queremos ser verdaderamente serios en nuestros análisis, tenemos que asumir una postura crítica que 
no ceda ante la tecnomanía. A pesar del optimismo de quienes están fascinados con la tecnología informacional y su "democracia consubstancial", el panorama no es el de una pieza de silicio pulida y reluciente, tan uniforme ella, sino el de la Wold Wide Web y su caótica estructura. El interés por la cultura que surge de entre los cables y los chips erraría el camino si olvida que todo producto cultural surge también de entre los sueños y anhelos humanos, lo que significa, por supuesto, que estarían plagados de los altibajos y distorsiones propios de nuestra naturaleza bumana. Eso significa que las sospechas estarían a la orden del día. Por ejemplo, y a pesar de la paradoja implícita, puede que haya mucho de conservador en el énfasis sobre la innovación que eventualmente tiende a "programar" las mentes de los "usuarios". Después de todo, identificar información y conocimiento puede resultar bastante útil para quien quiere estudiantes dóciles o trabajadores sumisos. Y esa misma actitud crítica es la que nos impele a pedir cuentas. ¿Sociedad de la información o sociedad del conocimiento? ¿Gente in-formada o personas conscientes? $\mathrm{O}$ como dijo el poeta:

\section{¿Dónde está la sabiduría}

que bemos perdido con el conocimiento?

¿Dónde está el conocimiento

que bemos perdido con la información?!

1. Thomas Stearns Eliot, citado por Emilio Lamo de Espinosa, en su artículo La sociedad del conocimiento: el orden del cambio, el cual presentamos en este número. 